\title{
Challenges of Economic Integration of Small and Medium Enterprises in Manufacturing Sector Tigray Regional State Mekelle City
}

\author{
Abrehet Mehari Gebreselassie \\ Lecturer in Ethiopia Civil Service University, Ethiopia, Addis Ababa; PhD Candidate at Azerbaijan State \\ University of Economics
}

\begin{abstract}
The purpose of this study is to assess the economic integration of small and medium enterprises in Ethiopia, in the case of Tigray Regional State Mekelle. The development of Small and Medium Enterprises (SMEs) in the manufacturing sector has been highly agenda on the Tigray Regional State to generate employment and reduce poverty. The goal of the economic integration of SMEs is have free movement of capital, labor finance, and service between SMEs in the region and outside the country and becomes a more efficient in the allocation of resources. This study was employed a qualitative research method conducted in Mekelle city, focusing on the challenges of SMEs. Collected data by interview 15 (10 SMEDA leaders and stakeholders) and eight focus group discussions with the SMEs council, including non-participatory observation of the researcher. The result also revealed that small and medium enterprises are operated in a problematic situation suffering from financial constraints and work premises are found out as a general challenge to all SMEs. Also, the commitment, capacity, and attitude of leaders at a different level to support and coordination for SMEs is weak. The critical problem of peace and security among the Ethiopian Regional Governments and neighboring countries hinders the market linkage among them. On the other hand, the dependency and rent seeking mentality of the SMEs to prepare a business plan and promote their products. The commitment, attitude, and capacity of the leaders at a different level to support and coordinate SMEs' activities is feeble. The researcher recommends that the regional government should establish specialized financial institutions and market supporting unit to help SMEs. Alongside the asset of the operators should be considered as collateral to solve the liquidity problem of the enterprises. Capacity building to operators and SMESDA leaders are very critical to internalize the experience gain from others to support SMEs efficiently. Work premises should be ready before the SMEs are established.
\end{abstract}

Keywords: Small and Medium Enterprise, Economic Integration of Small Enterprises, work premises

DOI: $10.7176 / \mathrm{JESD} / 11-4-14$

Publication date: February $29^{\text {th }} 2020$

\section{Introduction}

Economic Integration is the process whereby the economic barriers between or among economies removed to mutual exchange of capital, human power and information(SESRIC,2012)., strengthening the local SME markets (OECD, 2004), and help in protection of regional security (Dawit, 2017).In addition, Christoph (2010) suggested that economic integration can facilitate access to a larger consumer base, a greater share of qualified workers, additional sources of financing, and new technologies. In other words, economic integration can create an environment for existing firms to grow, solve common problems to enhance productive, improve quality product and compete in the market, and initiate for new firms to established. This alone cannot assure the growth of firms. It demands strong support and commitment from the government to help in searching the new market, demand forecast and get market information to become competitive.

Government of Ethiopia has set several national development goals to be achieved by 2025 . This includes attaining lower-middle-income status; diversifying and doubling the country's export capacity; lifting the contribution of the manufacturing sector from its current level of 5\% to $17 \%$, which turns Ethiopia into a leading manufacturing hub in Africa. Also, it creates decent jobs and a dynamic private sector that contributes to the growth and structural transformation (Tegay, 2018). A country like Ethiopia, where capital and foreign exchange are scarce and labor are relatively abundant, the most realistic and viable approach to kick-start industrialization and structural transformation into manufacturing sub-sectors rely on labor-intensive production technology (Alemzewud, 2018, p.2).Manufacturing provides new technology for other sectors.

But this sector hugely affected by various factors such as bad management practice, financial constraints and working promising which influences the productivity of the firm. Thus, the development of SMEs in the manufacturing sector has been a big agenda on the Ethiopian Government as a means of generating employment and reduce poverty. MSME Development Strategy was formulated in 2004 to addressing the difficulties and promoting the growth and expansion of MSMEs and then revised in 2011 (FDRE, 2012).

In line with this, the Government established Federal Micro and Small Enterprise Development Agency (FMSEDA) in 2005 on Proclamation 33/98 (Mesfin,2015) and then in 2008, the Regional Micro Small Enterprise 
Development agency (ReMSEDAs) also established at regional level to provide extension services to the sector (Adil 2007; Mulatu 2005).

Since, 2004 MSEs have shown tremendous development to be noted as the primary driving engines of the incredible economic growth, which have been registered over the last two decades now which highly crucial for playing a critical role in Ethiopia. However, the Government does not include Meddle Element in the 2004 strategies in the category which is too much recommendable to see the progress, and transitions of enterprises from Micro to Small and then to Medium (Amare, 2017).

Considering the above Small and Medium Enterprises (SMEs) development strategy in Ethiopia has been designed in 2015 and they were included in the Growth and Transformational Plan II (GTPII) to maintain the momentum of the rapid economic growth being registered in all sectors. As (Tsegay, 2015; Amentie et al, 2016) said SMEs are an engine of economic growth, jobs creation and poverty alleviation (World Bank, 2007; MoUDH, 2012; Cibela, 2016; Dawit 2017) mentioned SMEs as a seed and backbone of the private sector (Biru, Vugar etal, 2017) SMEs are a manifest of a thriving and dynamic economy which lay a fundamental foundation for the industrialized economy (MoUDH, 2012; Yared, 2018).

Maddison (2019) suggested in his Urgent Paper, seeing the importance and contribution of SMEs to national economies, there is need for governments to provide the necessary support to these firms and hence, enhance their capacity to penetrate in the competitive local and global market. Thus, Regional Government of Tigray has embarked upon the implementation of the Growth and Transformation Pan II designed in 2015/16 focusing mainly on the development of light manufacturing industries which is SMEs. But Eshetu and Mammo (2009) argue that "Ethiopia has failed to benefit from the phenomenal growth in the SMEs sector". This emerges from the fact that the sector lacks appropriate policy, to integrate into development strategy and sector-oriented support services agencies restrain the development and expansion of SMEs. Industry remained just 5 percent of GDP for most of the past decade. The country has not made significant progress in pulling labor out of agriculture into more productive and industrial jobs (Tsegay, 2018).

The share of employment in the manufacturing sector has changed only slightly unchanged since 2006 , at below 5 percent of total employment that the performance records in the region have been somewhat disappointed. It calls additional measures will take integrating and networking all stakeholders and Government through buyersupplier relation, interconnection among SMEs, and communities (GSTS, 2019). Nowadays, SMEs has operating in a difficult situation in unconducive business environment due to the government failure in addressing to the above overall problem.

This calls for urgent and systematic research on economic integration among SMEs' policies and strategies and practices in the area. Therefore, this research study focused on challenges of economic integration of SMEs in manufacturing sector in Tigray Regional State. Mainly SMEs engaged in textile and garment, constriction input, leather and leather products, wood and metalwork, and agro processing. To understand and assess the process of integration in the sector to give a better contribution to the right policy to achieve better results from the respective sector.

\section{Problem Statement}

Ethiopia is characterized as an undeveloped country, chronic poverty $23.5 \%$, with a high population (109 million) second to Africa, lack of investment capital, and have infant entrepreneurship and migration are all persistent problem of the country (Elias, 2015). Given this situation, we may not expect there is economic integration of SMEs as required and derived by SME members and actors at large. Economic development could be realized on the integrated effort of the regional government, private enterprises, capacity building, and financial institutions. Thus, development of SMEs in the manufacturing sector has been highly agenda on the Tigray Regional State to generate employment and reduce poverty and make it history. Eradication of poverty requires a multi-pronged approach and actions involving both macro and micro policy initiatives on different fronts. However, the underdeveloped nature of productive capacity and many working-ages absorbing into the productive sector is weak. low volume of growth of employment in manufacturing sector (GSTS, 2019). This makes it difficult to strengthen the economic integration of SMEs, which calls institutional set-up, skill capacity, infrastructure, and technology, management competency of the operators, active market strategies, and investing in technology (Arega et al., 2016). Research has been done in the area of micro and small enterprise. However, as per the knowledge of the researcher, studies in the field of the economic integration of SMEs in the manufacturing sector in Tigray Regional State have not been done before.

\section{Literature Review}

"SMEs are defined based on place (differ from place to place, i.e., country to country), time-specific, their turnover capital may increase or decrease because of inflation/devaluation and the situation of SMEs depend on the dynamic change of the country's economy through SMEs".

According to the new Development Strategy published 2011, SMEs are defined based on capital and Labor. 
Small enterprises are those with 6-30 workers and total capital, not exceeding 1.5 million Birr for manufacturing enterprise, while Medium enterprises have 31-100 workers with a total capital of less than 20 million Birr.

\subsection{Practice of economic integration among SMEs in the manufacturing sector}

Economic and integration theories

Economic integration theory goes through two (classic /static and dynamic) stages addresses the political and economic context. Classic /static explain the possible benefits of trade and investment effect of the economic integration of the country (Kosandi, 2012). whereas dynamic theory referred to the impact of economic integration on the regional cohesiveness; bring regional peace and stability, have power in the international market. In addition to the above, others deal with benefits and constrain of economic integration (Eduard,2016). For this study the researcher focuses on assessing effect and challenges for economic integration regarding SMEs in the manufacturing sector.

Balassa (1995) explains the effects of integration is increased economic growth, improve access to advanced technology, way of communication, market structure, increased competition and uncertainty. It also provides a better chance for sharing certain costs increase foreign direct investment flow, and improved productivity of SMEs. It is intended to lead lower price from production for distributors and consumers with the objective of improving the standard living of the people by creating a job. The other benefit of economic integration facilitates access to a larger consumer base, a greater share of qualified workers. This implies economic integration can create an environment for existing firms to grow, and become more productive (Hosny,2013). Furthermore, economic integration is a process of implementing a set of preferential policies to mutually exchange of goods and services between SMEs by removing the economic barriers (Afesorgbor, nd). However, it accompanies various challenges such as increased exposure to competition, political risk-limiting rules and regulations. The author suggested that the regional government of the state should create conducive environment among SMEs mutually exchange of goods and services between them

According to Margaret Lee,2014 economic integration includes a common market integration, to removal of any trade barrier between countries to have a regional cooperation to move their resource freely to have socioeconomic and political interests and a strategy and working on equitable distribution of costs and benefits among members (Lee 2003) cited by Dawit, 2017 and freedom of movement their resources.

If SMEs are effective in the integration process they can benefit from economies of scale, increased their competitiveness and lower costs that result in profitability. At the same time consumers can also benefit in the sense that the competitive environment brings those cheaper products, more efficient, innovate new products that increased choice of quality products. Furthermore, economic integration brings a striking increase in competition from imports, new foreign investors and strengthen the domestic market of SME (OECD, 2004). However, economic integration and its benefits are not fully applicable to integration because of the challenge of competition, market access and free trade and Human resources capability (Meier, 1990; OECD, 2004).

\subsection{Factors that affect economic Integration}

Competitiveness

Competitiveness is firms' capability to survive in the competition against their competitors. The factors that determine competitiveness are capital to finance, human capital demand who capacitate both in theory and practice, quality products demanded by consumer, competition among SMEs, supporting facilities provided by the stakeholders, and motivational system provided by (tax and subsidies). if the above factors easy SMEs can be capable to produce high-quality products, and innovative to meet market demands. Regarding the access of competitive market, SMEs can improve their production, change their market structure, and then increased their efficiency. Thus, economic integration of SMEs is achieved in medium- and long-term objectives $($ Marinov, 1999) but, Helleiner, 1999 argues that the small and medium enterprises are an unequal partner who is forced to adjust to the economic and price structure in the larger market.

The World Economic Forum (WEF) recently published their Global Competitiveness Report for 2017-2018 regarding the Global Competitiveness Index assesses the competitiveness of the landscape of 137 country's economies and it provides unique insight into the drivers of their productivity and prosperity. Whereas, Report,2019, provides an annual assessment of the drivers of productivity and long-term economic growth covered the socio-economic elements such as institutions, infrastructure, ICT adoption, macroeconomic stability, health, skills, product market, labour market, the financial system, market size, business dynamism and innovation capability. (WEF,2019). With a score of 84.8, Singapore is the world's most competitive economy in 2019, overtaking the United States, which falls to second place. Hong Kong SAR (3rd), Netherlands (4th) and Switzerland (5th) round up the top five and Denmark (81.2) the 10th next to United Kingdom (81.7)

Market

The market is determined by the number and nature of sellers, number and nature of buyers, the nature of the product, conditions of entry into and exit from the market, and economies of scale. High levels competition in 
export and import markets erode SMEs' competitiveness. Thus, SMEs requires to have certain competitive strategies to compete in the market (Theresia Wore Damayanti, 2018). For example, Asian countries design a Strategic Action Plan for SME Development such as promote productivity, technology and innovation; increase access to finance; enhance market access at local and global; enhance policy and regulatory environment; and promote entrepreneurship and human capital development .Additionally, existence of market linkage between enterprises, domestic and international markets helps enterprises to distribute their products (MoUDH 2016).Berhun.et al (2014) also indicated that the existence of strong supportive government institution helps searching new market, demand forecasting, and market information. Marketing involved creating a marketing strategy focused on up-to-date events through social media needs social network, people's interaction, share to others and provide to community Anteneh, 2017 and MoUDH ,2016) argued that most enterprise failed or remains stagnant because of inadequate market for their products, problem of searching new market and lack of market information. This emanates from lack of cash flow, marketing expertise, business size and strategic customerrelated problems (Dole et al., 2006).

Trade factors

Using the share of inter-regional trade, Lipsey (1960) suggested that an integration will bring more benefits in terms of well-being to the society if the share of local trade is growing, and the trade barriers such as low level of economic development; inadequate transport infrastructure and facilities; foreign currency control and other restrictions on imports; inadequate marketing and the lack of standardization are removed. Thus, trade flows between regional states engaged in an integration process will likely increase. Free trade and market among SMEs combined with high tax for imports should give temporary protection to emerging industries as well as a market that is big enough to support the future industrial development. This process is referred to as "import substituting industrialization" (Rueda-Junquera, 2006) and gives enough time for the development of the manufacturing sectors of SMEs.

Human capital factors

The other issue related to the determinant of economic integration is the capacity of SMEs to innovate and adapt technology for growth of enterprises and to have an appropriate machinery and equipment's. A key determining factor of productivity is the ability of an economy to supply the skills needed for companies to grow and to thrive. Ethiopia has made significant progress in expanding access to education, but challenges remain. A more literate and trainable labor force would not only increase productivity in Ethiopia, but also make the country more attractive to international firms seeking to invest in Africa. Yet, skills shortages in Ethiopia constitute a key constraint to growth and improved productivity in the manufacturing sector despite the country has made significant progress in expanding access to education. Cristina et al,2007, study on Manufacturing Innovation in the New Urban Economy, Responses to Globalization, mentioned that training and skills upgrade need to focus on customizing training to target both the core competencies of firms, and those skills needed to meet changing business demands. Industry clusters provide a 'thinking business space' in which to design potential solutions to skills shortages, lack of attraction of new talent, and the challenges of up-skilling and re-skilling the workforce. Berihun et al. (2014) also added that most enterprise was failed or stagnant because of lack of skill manpower to handle new technology, lack of skill to operate the appropriate machineries.

\subsection{Enabling Business Environment}

ADB (2014) mentioned that the Donor Committee for Enterprise Development (DCED) describes that business environment as the complex interplay of policies, laws, and regulations that affect business development in a given place and the institutions responsible for their enactment at the international, national, regional, and municipal level. A weak enabling business environment (legislation, policies, regulations, and support institutions) are the key constraint on the development of the SME sector. Sethuraman also supported poor enabling environments are growth barriers and hence negatively According to the ILO (2000) report, the three pillars of enabling business environment includes institutional frameworks determine effectiveness and efficiency of business infrastructures such as business development support (BDS), microfinance institutions, marketing and research development. A good institutional framework enables access of these services to the needy with minimum cost whereas poor institutions in general, lead to higher transaction costs (ILO 2002; OECD, 2018)

Ethiopia has also established a Federal and Regional Small and Medium Enterprise Developmental Agency at Federal (1998 E.C) and Regional (2000 E.C) level to support and coordinated SMEs (MoTI,2012).

The lack of a clear policy and legal framework hindered development of the SME sector across countries, Countries often lacked an effective policy, strategy, and institutional framework for SME development; diverse policies and programs were not integrated or coordinated; there was limited institutional capacity and resources; and most countries lacked a statistical database on SMEs and often more favorable to large enterprises and multinational corporations. Though the registration were easy for SMEs, land registration, leasing, financing was difficult and bureaucratic in Ethiopia, Tigray for SMEs resulting in a high cost of compliance and low productivity but better for FDI. And weak SME skills and capacity, and their lack of access to markets, information, and 
technology have often been cited as common constraints.

The ILO has recently carried out the review of policy and regulatory environment in eight countries around the world as its global programme to determine whether the conducive environment contributes to the creation of quality jobs in micro and small enterprises (MSEs). For example, the policy review in Nepal has benefited in terms of formulating an appropriate strategy from the international experience gained in such work in several countries, including the countries in South Asia and a reviewed the policies, legislations and procedures; made an assessment of the MSEs business environment and their employment contribution; made a survey of the MSEs and a gap analysis (ILO, 2003). World Bank Group 2015 mentioned that the private sector is expected to play a key role in Ethiopia's journey to become a lower middle-income country in 2025. However, Ethiopian firms face significant financial constraints, because financial institutions do not accommodate Small and medium enterprise needs. In adequate support from financial institutions, SMEs are not able to grow, or create more job opportunities.

As World Bank's Investment Climate mentioned that SMEs as a fundamental foundation and seed for manufacturing industries. However, the quality, and coverage of infrastructure is low, the inadequacy stems largely from resource and capacity constraints leads most SMEs low productivity, and inefficient allocation resource that lacks SME's competitiveness. This is a major impediment to the expansion of production for SMEs, and the development of export capacity (CBC, 2013).

The vision of Tigray Regional State is to create a society where extreme poverty becomes history and every citizen has access to a job. The regional government of Tigray now looking into the future and has embarked on development strategies, evaluated the implementation of policy and strategies organized worldwide Tegaru Diaspora and internal and external academicians conference of aimed at transforming Tigray into the most dynamic and technology more advanced region in Ethiopia. But underdeveloped nature of productive capacity, absorbing unemployment into the productive sector is a challenge of the region (GSTS, 2019). This makes difficult to strengthen the economic integration of SMEs in the manufacturing sector which calls systematic research in this area.

\section{General Objective of the Study}

The main objective of this study is to identify the challenges of economic integration of Small and Medium Scale Enterprises in Tigray Regional State, Mekelle City.

Research questions

What is the practice of economic integration among SMEs in the manufacturing sector?

What are the major challenges that hinder the implementation of SMEs strategies in the manufacturing sectors?

\section{Methodology}

This study was employed a qualitative research method conducted in Ethiopia: Tigray Regional State Mekelle city, focusing on the challenges of Economic Integration of SMEs. Collected data by interview 15 key informants (10 SMEDA leaders and stakeholders) and eight focus group discussions with the SMEs council by asking semi structure questions. These key informants have a specialized knowledge and the positions they occupy in their respective fields are crucial for this issue, It also used non-participatory observation of the researcher. Data collected from interview, FGD, and non-participatory observation were transferred and organize into text. Then follow by coding, give meaning, editing, categorizing and interpretation follows. The secondary data gathered were presented, analyzed, described and interpreted through conceptualization, explanation and interpreted qualitatively.

\section{Major Findings}

The responded said that policy and strategies are applicable to the region's SMEs and gets out of poverty if it works out properly but, the strategy was not fully responding to the need of SMEs. it lacks proper implementation due to lack of skilled experts, commitment of the leaders especially at low level position. SMEs are the missing element in the strategies, especially with related to finance, no support rather the existing strategies focus on micro, large-scale enterprises and FDI. The linkage of SMEs strategy with other development sector is weak even though the interest of government very high due to the lack of act by government officials and the less effort of SMEs. The problem of the strategy is started from the establishment of SMEs. No proper study is conducted before SMEs are established such as the criteria to be established, who support them? do the supporting unit have a capacity in knowledge, skill and administrative system better than the SMEs.

The establishment of SMEs mostly not by the initiation of themselves but encouraging by government even though it has its own advantage and disadvantage. For example, recently SMEs which has 200 members established by the city Administration was separate and disorganized. This implies, the criteria are not clear by them, unwilling to establish the business with others and the lack of support from the government officials. SMEs development should be provided with maximum efforts to the basic supports despite the sector level growth, The key informants indicates that the concerned public sector leaders at all levels should acquire the knowledge and 
skills concerning the strategy and support package, holding positive attitude so that they could work closely with the Small and Medium manufacturing operators, council, and key stakeholders In addition to this, results obtained from the interviews, all the interviewees admitted that there are limited knowledge, skills, and attitude among the concerned leaders. Especially at low levels and the key implementers within the key supportive institutions and councils regarding the SMEs issues stated in the national industrial strategy, packages, guidelines and Kaizen philosophy. They lacked the necessary skills which enable them to organize stakeholders, catalyze initiatives, and devise mechanisms and to go through the path of ensuring and promoting the development of SMEs. leaders of the city did not work at an expected level to enable the SMEs to play significant role in the development activities. Commitment is a critically important factor that matters effective performance in the achievement of organizational goals. Economic integration is determined by the leaders will and commitment. key informant interview leaders and FGD participants presented a consistent idea that leaders in the city lack commitment to support SMEs in fully. Weak follow-up and evaluate the performance of their activities and wide gaps in demand and provision of actual service and poor coordination among stakeholders.

All the interviewed leaders said SMEs facing difficulties to get internal and external credit /loan since the cash inflow and savings of the SMEs sector is significantly low due to lack of teamwork among SMEs manufacturing agency and financial institutes, lack of detail understanding of the finance package on saving and loan services, and the guarantee fund proclamation. Tigray MFI regulation of loan provision requires $20 \%$ of the total loan and $15 \%$ for finance leasing is to be held as advance saving from operators which creates a shortage of working capital and insufficient cash balance to acquire fixed assets. loan process takes a longer time and bureaucracy in the provision of foreign currency.

The availability of land has been cited as one of the top constraints for SMEs development and expansion. lack of access to working premises. The leaders said that the lease rent of land rises from 0.75 to 300 birr per meter squared, which is unaffordable by the operators, SMEs are established before land is prepared. On the other hand, SMEs have a problem with a rent-seeking mentality by the SMEs operators to sell the land without value added. Lack of coordination and communication among Federal Regional and Mekelle city Municipality. The existing land was remaining idea due to infrastructure problem like road, electricity, water and telecommunication. The above problems were leading operators to rent land in the city center and limit their production as observed by the researcher.

SMEs in the manufacturing firms were asked to identify networking among actors. Most SMEs have limited experience in creating a partnership and networking with other regions and international SMEs to adopt technical capacity, knowledge, and skills to solve common problems and introduce a new way of thinking and creativity. In addition to this horizontal and vertical networking with inputs supplies, agriculture input suppliers, and industrial parks, large-scale enterprises are limited.

To ensure economic development, introduce a new way of thinking and creativity, producing skill manpower, minimize unemployment are some of the policies and strategies' primary concern. Conducting active, continuous, and appropriate training help SMEs to enhance production and sales services, supplying new products based on market demand is vital. Training has paramount importance to fill knowledge, skill, and attitude gap, equipped with technology, and to have creative and confident citizens to involve in SMEs operation. Providing appropriate training service to SMEs can enable them to work in an integrated way by sharing experience and exchange material to solve common problems on time. Additionally, Training can help SMEs to grow, develop, and transfer to the next level of business class.

Accordingly, all the leaders indicated challenges that they are facing in support instrument providing with, failure in giving training based on need and result-oriented, and identifying the gap, problem of pre and on the job training with different training, such as entrepreneurship, business management, skill training, Kaizen principles and attitudinal change. The interviewed leaders and FGD stated that the support service is not well known by the users, absence of readiness to accept and use new technology. The interview result shows that most of the SMEs manufacturing enterprises are domestic market-oriented and less internationalized. Besides, detail understanding of strategy and package (absence of the required skill, attitude, and knowledge on the formulating procurement guidelines in 2011. Lack of effective communication, and the problem of having workable strategic planning. Additionally, they use weak marketing strategy and SMEs operators have developed a dependency on the government to link with partners and promote their products.

Shortage of raw materials in the domestic market firms is increasingly dependent on imports. respondents critically stressed that political instability among regional governments and neighboring countries is one of the main problems for SMSs market linkage and shortage of foreign currency, SMEs are limited in domestic market and are highly competitive with each other's rather support each other and exchange their factor of production to solve the common problem.

Technology, as related to SMEs, is defined as the ability /capability to translate and convert ideas into tangible goods and services. From this, one can understand technology is an essential prerequisite for SMEs to be competent enough in today's technology era and globalized world. SMEs must grow to larger enterprises through 
improvement in product quality and productivity, as well as replacement of the outdated technologies with the new ones, along with the supports that help them compete in the market.

Accordingly, the interviewed leaders and all the participants of FGD stated that the support service is not well known by the users, absence of readiness to accept and use new technology. From the supportive institutions, they Lack effective communication and the problem of having workable strategic planning to introduce the acquisition of modern technology. They all agree that the key challenges faced while supporting the business operators on technological development and growth are that the support instruments are not put in place by the yearly plan to achieve. Also, industrial extension service problems, weak facilitating the establishment of shared facilities, and failure of supports related to technological development (development, successful copying, and adoption of technology) are some of the challenges. Additionally, the researcher had assessed secondary data of MCSMMIDA (2019), annual report the emphasis on technological development and growth was not achieved due to weak attention of the concerned leaders.

This implies support related to technological development and industrial extension service is low. Hence, it demands maximum effort and effective communication to the development and successful copying and adoption of technologies.

One-stop center service is a service established to provide SME to be involved in production and services legally, to be beneficiary of government support, and to enable to provide services in an integrated, transparent, and efficient way. The one-stop center is part of the organizational structure of SMMIDA that is organized at the sub-city level designed that all the necessary services to enterprises to be provided at this center (MCSMMIDA, 2019). Concerned supportive institutions, which have a direct stake to enterprises (TVET, MFI, and SMMIDA), are expected to deliver the required service by the business enterprises in the one-stop center.

Regarding the one stop centers, all interviewees have the same outlook about the failure of the centers to provide all the necessary services at one place and absence of signs inside the centers that say where customers should go. It is not on the position to provide a warm and welcoming reception to accommodate the customers and the lay out service delivery set up does not allow the customers to go up and down to many offices for service. According to Meier (1990), marketing linkage is one of the determinants of the economic integration of SMEs that has a potentially positive impact on employment, productivity, income level, and competitiveness. While one of the support services that are given to SMEs by the government. Marketing in this context is to realize the development of business operators; there should be a suitable market as it is difficult to create wealth, and job opportunities without the availability of a sustainable searching market are the primary role of the manufacturing industry.

The government of Ethiopia has been intervening in three ways to address market access problems of particularly micro and small enterprises (Berihu et al., 2014). First, the government itself buys goods directly from SMEs. Federal Public Procurement Administration Agency has set a rule that forces public institutions to source a portion of their annual procurement from SMEs. That is, SMEs are given priority in government procurements (MoFED, 2010). Second, the government tries to link SMEs with large enterprises in the market in the form of subcontracting and input suppliers. FeSMMEDA has introduced a new directive on franchising, sub-contracting, and out-growth linkage with large and medium enterprises. This was practiced mainly in the construction industry. For example, 40 of the construction works in condominium housing construction projects that fundamentally involve finishing such as sanitary, electric installation, and other finishing works were given to SMEs. Apart from market linkage with government projects, large enterprises such as Mesfin Industrial Engineering, Metal Engineering Corporation, Sugar Corporation, and MAA Garment were noted as private market linkage creators by significantly involved sub-contracting of some of their works to SMEs. However, there is no strong marketdriven linkage between SMEs and Large Enterprises. Thirdly, several bazaars and trade exhibitions have been organized by SME development agencies to promote products and to link them with large enterprises and foreign buyers.

The interview result shows that most of the SMEs manufacturing enterprises are domestic market-oriented and less internationalized. They are facing in support instrument providing market linkage due to non-value adding market system, lack of work commitment, detail understanding of strategy and package (absence of the required skill, attitude, and knowledge on the formulating procurement guidelines in 2011).Thus there is a failure in promoting their product, lack of effective communication, and the problem of having workable strategic planning. They use weak marketing strategies (i.e., quality and pricing). The SME operators have developed a dependency on the government, and the sector-wise investigation showed that the development of related industries is poor; shortage of raw materials in the domestic market firms is increasingly dependent on imports, which could have been produced domestically. Despite endowment, the agricultural sector is not able to produce enough quantity and quality inputs to meet the demand for the small and medium manufacturing industry; as a result, their products do not qualify international competition.

Additionally, all the participants of FGD stated that no more than $5 \%$ of the manufacturing establishments are participating in the export market despite different incentives for exporters. Similarly, there are only a handful 
of enterprises in Tigray which are involved in exporting the concerned supportive sector. The involved body has failed to undertake the task of market linkage based on the formulated procurement guidelines, lack of integration, and functionality of the council to tackle the constraints encountered.

Finally, the interviewees suggested that political instability among regional governments and neighboring countries is one of the main problems for SMSs market linkage, shortage of foreign currency since reducing export goods produced, and negative attitude of the community towards to locally produced products.

\section{Conclusion}

Industrial transformation is not merely about increasing the number of manufacturing enterprises or earning hard currency from manufacturing exports. The value addition is more in input, process, and transformation. $1 \%$ change to manufacturing has multiple effects on the economic transformation of the country. The resources of Tigray Regional State are land, human power, air, and water, but have not technology. The region started a business from what it has the existing resource, which is getting input from agriculture but no back and forward linkage between agriculture and the manufacturing industry. Outcome could no becomes equity, fairness in income distribution to become an inclusive economy, and poverty reduction in general. The reason is policy and strategies were not implemented properly.

The knowledge and capacity of the implementers as the interviewee said were below the SMEs operators. This was discouraged and made unhappy to the operators.

Enhancing the competitiveness of Small and Medium-Sized Manufacturing Enterprises in economic integration have indispensable roles in the development. This can be implemented when leaders perform their roles properly in a systematic way to help SMEs in searching market and fulfill the production factor that moves towards attaining of their objective

Most of the SMEs operator does not have knowledge which is an essential requirement for the success of their business such as : 1.Technical know-how (how to design and plan because of their education back ground ,entering the firm through practice); 2. basic knowledge of skill of software and mathematical knowledge and human ware (to plan); 3.organizer ware (to understand and know how much human aspect is needed and input of the production and service);4.technology hardware (know-how of the machine they operated )it depends of the technology simple or complex; 5.market linkage within and outside the region; 6.financial problem because medium enterprise were missing element in the strategy financially) and 7.work premises place ,most of SMEs are worked at home and others suffered by high rent as observed by the researcher..

The other problem is the political instability arising among regions and the unstable open and closed of EthoEretria border since Tigray found within this border. After 27 years conflict between Ethiopia and Eritria, in September 2018 the border was opened, and SMEs got access to market and create link with other enterprise and sole proprietors. After few months the border again closed on December 2018 and to that extent the ordered material produced were not delivered, beside this, conflict among regional governments within the country also hinder the free movement of goods and services. SMEs obliged to keep their production in store which is incurred caring cost and tied up their capital. This may lead outdate and obsolesce. These all hinder the economic integration of SMEs.

\section{Recommendations}

Based on the findings and the knowledge acquired from the literature, recommendations are proposed to be carried out to resolve the challenges which are identified.

Implementation of the policy and strategies should speed up to achieve its objective with coordination and collaboration of stakeholders, timely information, and promotion related SMEs through all concerned bodies. The support should be through scientific knowledge to create productive enterprises to produce quality products and become competent in the local and international market who create job opportunities for future generation and sustainable development of the country

SMESDA should be capacitate the leaders and experts those engaged in SMEs operations to provide adequate support, committed and persistent in implementing and coordinating different activities related to economic integration among SMEs in the manufacturing sector.

Leaders should encourage and promote active involvement of SME council and proper coordination of stakeholders, private sectors, and emphasize on capacity building and skill development of support providers and SMEs and also close support, follow up and evaluation to check SMEs track and to reduce their challenges.

SMEDA should aware SMEs that the benefit of integrating each other and organized in developmental circle in the city can help them to support common resources, experience sharing among them, knowledge and technology transfer, purchased input in bulk to reduce costs, have got one stop service and subcontracting from large scale enterprises through training and workshops to bring sustainable economic integration

The government should prepare the land for SMEs operator and feasibility study on work premise, access to finance and infrastructure before establishing the operators, and the lease price of land should consider SME 
operators' financial capacity.

The machine they had and the shade they used should be considered as collateral to get loan. The Regional government should establish separate financial institution to facilitate SMEs productivity and market competition.

Supporting SMEs must be selected based on the criteria and leave them to competition's among SMEs makes them competitive in the market. Since all SMEs are not competent, the resources should not give to all. It must be selective, live to competition through a research study, follow-up and control also necessary otherwise, it leads to rent-seeking, some of the operators are sold the given land to others without added value.

SMEs should create linkage with the region's large-scale enterprises through forward and backward (subcontracting and outsourcing). Leaders should give emphasis to capacity building and skill development of support providers and SMEs. The training program should aim to enable potential SMEs particularly youth to develop sustainable business idea and SMEs start up.

The business operators should be ready for change and accept new technologies. The operators should create an ability of independence rather than waiting for another to offer them (be visionary, hard work and persistence) There should be a strong relationship and networking with inputs suppliers. SMEs should work together, building team sprit to integrate complementary asset or investment to promote jointly with common resources.

Rent seeking should be eradicate from both the SMEDA officials, SMEs operators and supporting unities. The people should trust the public officials that clear from corruption and the officials also should approve this.

An urgent action should be taken by government officials at different level to come into dialog among regions and between neighboring countries to have economic and political stable environment within and outside the country.

\section{Reference}

ADB (2014): Support for Small and Medium-Sized Enterprises, 2005-2017: Business Environment, Access to Finance, Value Chains, and Women in Business, Linked Document, A Small and Medium-Sized Enterprises in Asia and the Pacific: Context and Issues

Adil Yassin. 2007. Challenges and constraints of micro and small-scale enterprises in Tigray: The case of two Sub-cities' Industrial Zones. MA Dissertation. Mekelle University

Alemzewud Melesew (2018): The determinant of Technical Efficiency of Manufacturing Firms in Amhara National Regional State, Ethiopia, Ethiopia Economics Association, 2018 ISBN 978-99944-54-66-2

Amare Abawa(2017):Micro, Small and Medium Enterprises(MSMEs)Development Strategies in Ethiopia: Retrospective and Prospective Analysis ;Mangalore University Department of Commerce Mangalore, India ,IRACST International Journal of Commerce, Business and Management (IJCBM), ISSN: 2319-2828 Vol. 6, No.1

Amentie C, Negash E, Kumera L (2016) Barriers to Growth of Medium and Small Enterprises in Developing Country: Case Study Ethiopia. J Entrepreneurship Organize Manag

Biru Ashenafi(2014):The Impact of Subsidy on the Growth of Small and Medium Enterprises (SMEs) Department of Cooperative Studies, College of Business and Economics Mekelle University, Ethiopia. Journal of Economics and Sustainable www.iiste.org ISSN 2222-1700 (Paper) ISSN 2222-2855 (Online) Vol.5, No.3, 2014

Christoph Ungerer (2019): Economist for the Macroeconomics, Trade and Investment Global Practice in the Europe and Central Asia region,World Bank 7/12/2019 https/www.brooking.edu.

Cibela Neagu(2016): The importance and role of small and medium-sized businesses; Theoretical and Applied Economics Volume 23 (2016), No. 3(608), Autumn,

Dawit Ayalew (2017): Economic Integration in East Africa: The Case of Ethiopia and Kenya Syracuse University June 2017 SURFACE Development

Elias Berhanu (2015): Local Economic Development in Africa, Enterprise, communities and Local Government, Netherlands ISBN 90-423-0280-1

FeMSEDA, 2011.Micro and Small Enterprises Development Strategy. Addis Ababa: Micro and Small Enterprises Development Strategy of Ethiopia.

FDRE,2012 a Ministry of Urban Development and housing Micro and Small Enterprise Development Policy \& Strategy Second Edition March 2012,

Federal Democratic Republic of Ethiopia (FDRE), Ministry of Finance and Economic Development (MoFED). (2013). Growth and Transformation Plan report.

GSTS (2019): Book of Conference Highlights of The 2nd Grand Confernce of Global Society Of Tigran Scolars Towards Building Sustainable and Knowledge -Based Economy and Society in Tigrai 28th July -1st August Mekelle ,Etiopia

Hosny, A.S. (2013) Theories of Economic Integration: A Survey of the Economic and Political International Journal of Economy, Management and Social Sciences Vol.2 No 5

Maddison Zara (2019) :Small and Medium Enterprises (SMEs) Analysis Urgent Paper, July 23,2019 
www.urgentpaper.com/challenges-for-smes

Mesfin Seyoum (2015): Challenges and Prospects of Small Enterprises in Ethiopia: A Study of Entrepreneurs in Tigray Region Submitted in accordance with the requirements for the degree of Doctorial of Philosophy in the Development Subject Development Studies at the University of South Africa October 2015

MoUDH (2012): Government of the Federal Democratic Republic of Ethiopia Ministry of Urban Development and Housing SMEs Development and Strategies.

OECD, 2004: Conference of Ministers Responsible for Small and Medium-Sized Enterprises (SMEs): Promoting Entrepreneurship and Innovation SMEs in a Global Economy: Towards More Responsive and Inclusive Globalization Istanbul, Turkey 3-5 June 2004

OECD (2018): Discussion Paper Small and Medium Enterprises Ministers Conference 22-23 February ,2018 Mexico City Enabling SMEs to scale up Plenary session 1

SESRIC (2012): Economic Integration and Export Behavior of SMEs: The Case of EURO Workshop on Enhancing the Competitiveness of Small and Medium Sized Enterprises in the OIC Member States12-14 June 2012, Ankara, Turkey

Tsegay Hagos (2018) Ethiopian Herald report on SMEs Driving Force for Realization Renaissance,22 April 2018 Ethiopia

Tigray (2018): Transforming Industry and Investment Tigray; Challenges, Prospective, Policy Options and Actions Final Report June 2018

Vugar Bayramov, Rashad Hasanov, Leyla Aghayarli, Zaur Kadyrov, Ismayil Aghahasanli, Sanan Isayev (2017) :A Comparative Study on Development of Small and Medium Enterprises (SMEs) in Azerbaijan

YaredTeshome, (2018) : Challenges and Opportunities of Micro and Small Enterprises Strategy in Ethiopia Urban development, the case of Ambo Town, Oromia, Ethiopia\# Mysore University, Institutes of Development Studies (IDS), Karnataka, India DMIMD Journal of Management Volume 9, Issue 1, March 2018 